\title{
Projected changes in frequency of suitable snowmaking conditions for the Australian Alps
}

\author{
$\underline{\text { F. Ji }}^{\text {a }}$, T. A. Remenyi ${ }^{\text {b }}$, R. M. B. Harris ${ }^{\text {b }}$, J. P. Evans ${ }^{\text {c }}$, A. Di Luca ${ }^{\text {c }}$ K. Beyer ${ }^{a}$ \\ ${ }^{a}$ NSW Office of Environment and Heritage, Sydney, Australia \\ ${ }^{b}$ Antarctic Climate and Ecosystems Cooperative Research Centre (ACECRC) \\ ${ }^{c}$ Climate Change Research Centre and ARC Centre of Excellence for Climate System Science, University of \\ New South Wales, Sydney, Australia \\ Email:fei.ji@environment.nsw.gov.au
}

\begin{abstract}
Observations have shown a clear increase in maximum and minimum temperature, and a decrease in rainfall and snow for the Australian Alps. Available future snow projections from different projects also demonstrate decreases in snow cover, snow depth and snow season in the future. In order to adapt to declining natural snow cover, snow making is playing an increasing role to sustain the ski industry.
\end{abstract}

The viability of conventional snowmaking is determined by the frequency of wet-bulb temperatures suitable for making snow. In this study, we used outputs of 12 historical and future Regional Climate Model (RCM) simulations (each with three time periods: 1990-2009, 2020-2039, and 2060-2079) from the NSW/ACT Regional Climate Modelling (NARCliM) project to investigate changes in frequency of suitable snowmaking condition for the Australia Alps. The number of hours suitable for snowmaking was calculated (based on threshold temperatures, such as $-2{ }^{\circ} \mathrm{C}$ ) for a historic period (1990-2009) and two future periods (2020-2039 and 2060-2079) for each of the 12 simulations. These time periods were compared to investigate if the frequency of suitable snowmaking changes into the future.

The results show that there is a substantial decrease in the frequency of suitable snowmaking conditions for the Australian Alps, with some areas showing larger decreases than others. The major differences between the projections are associated with the driving GCMs, suggesting that the large scale circulation plays a dominant role in the variation of snowmaking conditions.

Keywords: $\quad$ Wet bulb temperature, snowmaking, Australian Alps, NARCliM, ensemble mean 


\section{INTRODUCTION}

The Australian Alps is the highest mountain range in Australia. It comprises only about $0.16 \%$ of Australia in size, however, it is an important zone for ecosystem, biodiversity, energy generation and winter tourism. The region contains unique Australian ecosystems and iconic species such as the pygmy-possum. The Snowy Hydro Scheme collects and diverts water from rainfall and snowmelt into the Murray and Murrumbidgee Rivers, providing irrigation resources for the Murray-Darling Basin, the largest agricultural region in Australia. Australia's most popular snow holiday destination and the southern hemispheres largest resorts are all located in this region. The existence of the alpine resorts provides significant benefits to regional areas adjoining these resorts. Many of the alpine shires have high levels of structural unemployment so the alpine industry is important in improving employment outcomes for residents of these regions (NIEIR, 2006).

Seasonal snow in the Australia Alps is critical to some species and winter sports and has been the subject of numerous studies investigating long-term climate variability and possible future change. A series of previous studies examined long-term snow depth observations from a limited number of sites in the Australia Alps (Ruddell et al 1990; Nicholl et al 2005; Hennessy et al 2003, 2008; Davis et al 2013, and Fiddes et al, 2015). These observations begin in the 1950s and 1960s and generally show statistically insignificant decreases in snow depth until the late 1980s. A recent report focussing on Victoria demonstrated that since about 1985 maximum snow depths have declined and the snow season has finished earlier as temperatures have increased across Australia (Bhend et al. 2012). A number of studies also investigated the future climate impact on snow in the Australia Alps (Whetton et al 1996; Hennessy et al 2008; Fiddes et al 2015). These studies all use Global Climate Model (GCM) projected future climates to estimate the climate change for the Alps despite the GCMs having no representation of the alpine region within them. All of these studies project large decreases in snow cover into the future which will have significant impacts on alpine ecosystems (Pickering 2007; Slatyer 2010). Timbal et al. (2016) presented estimates of future climate change from both GCMs and a statistical downscaling method over Victoria. The statistical downscaling often has a larger decline in precipitation than the GCMs. This suggests that the use of GCMs to estimate future change may not be appropriate for the alpine region.

Recently Di Luca et al (2017) used 10km resolution simulations from the NSW/ACT Regional Climate Modelling project (Evans et al 2014), hereafter NARCliM, to evaluate simulated snow cover and snow depth and undertake future climate projections. Their results show that snow cover extent and snow depths decreases by about 15 and $60 \%$ by 2030 and 2070 relative to 2000 . The large decrease in snow cover extent and snow depths will substantially impact on winter ski business. Furthermore, regional climate modelling outputs presented by Harris et al (2016), project changes to occur in variables important for snowmaking (e.g. temperature, precipitation and snow cover) at six Victorian alpine resorts by the end of century (2070-2099) compared to the baseline period (1961-2010).

Snowmaking is now a common practice and an increasingly important function at Australian ski resorts to ensure seasonal length and viability of snow cover to meet the requirement of winter ski sports. Weather conditions are undoubtedly critical to make snow even if snow can be made at any temperature nowadays. Wet bulb temperatures below $-2{ }^{\circ} \mathrm{C}$ were considered suitable for snowmaking. In this study, we will use $10 \mathrm{~km}$ resolution NARCliM simulations to assess how suitable snowmaking conditions will change under future climate for the Australian Alps.

\section{DATA}

The outputs from NARCliM are used to calculate wet bulb temperature. In NARCliM, simulations from four CMIP3 GCMs were used to drive three regional climate models (RCMs) to form a 12-member GCM/RCM ensemble (Evans et. al. 2014). The four selected GCMs are MIROC3.2, ECHAM5, CCCMA3.1, and CSIROMK3.0. For the future projections the SRES A $2^{1}$ emission scenario was used. The three selected RCMs are three physics scheme combinations of the Weather Research and Forecasting model (WRF). Each simulation consists of three 20-year runs (1990-2009, 2020-2039, and 2060-2079). The 4 GCMs were chosen based on a number of criteria: i) adequate performance when simulating historic climate; ii) most independent; iii) cover the largest range of plausible future precipitation and temperature changes for Australia. The three RCMs (Table 1) correspond to three different physics scheme combinations of the WRF V3.3 model (Skamarock et al. 2008), which were also chosen for adequate skill and error independence, following a comprehensive analysis of 36 different combinations of physics parametrizations over eight significant ECLs (Evans et al. 2012; Ji et al. 2014).

\footnotetext{
${ }^{1}$ Scenario A2 described in the Special Report on Emissions Scenarios (SRES) by the Intergovernmental Panel on Climate Change (IPCC).
} 
For the selected three RCMs, the WRF Double Moment 5-class (WDM5) microphysics scheme and NOAH land surface scheme are used in all cases. Other parameterization combinations are shown in Table 1.

Table 1. Three selected WRF physics scheme combinations

\begin{tabular}{|c|c|c|c|c|}
\hline $\begin{array}{c}\text { Ensemble } \\
\text { member }\end{array}$ & $\begin{array}{c}\text { Planetary Boundary layer physics / } \\
\text { Surface layer physics }\end{array}$ & $\begin{array}{c}\text { cumulus } \\
\text { physics }\end{array}$ & Micro-physics & $\begin{array}{c}\text { Shortwave / Longwave radiation } \\
\text { physics }\end{array}$ \\
\hline R1 & MYJ / Eta similarity & KF & WDM 5 class & Dudhia / RRTM \\
\hline R2 & MYJ / Eta similarity & BMJ & WDM 5 class & Dudhia / RRTM \\
\hline R3 & YSU / MM5 similarity & KF & WDM 5 class & CAM / CAM \\
\hline
\end{tabular}

We acknowledge that the results are model dependent (as all model studies are) but through the use of this carefully selected ensemble we have attempted to minimize this dependence. By using this model selection process we have shown that it is possible to create relatively small ensembles that are able to reproduce the ensemble mean and variance from the large parent ensemble (i.e. the many GCMs) as well as minimize the overall error (Evans et al., 2013a).

Some initial evaluation of NARCliM simulations shows that they have strong skill in simulating the precipitation and temperature of Australia, with a small cold bias and overestimation of precipitation on the Great Dividing Range (Evans et al. 2013b, Ji et al. 2015). The differing responses of the different RCMs confirm the utility of considering model independence when choosing the RCMs. The RCM response to large scale modes of variability also agrees well with observations (Fita, et al. 2016). Through these evaluations we found that while there is a spread in model predictions, all models perform adequately with no single model performing the best for all variables and metrics. The use of the full ensemble provides a measure of robustness such that any result that is common through all models in the ensemble is considered to have higher confidence. However, there has been no evaluation of the model performance specifically for wet bulb temperature as there are no gridded observations for web bulb temperature available.

For ease of reference in this paper, the simulations driven by the same GCM were referred to as "GCM simulations", the simulations using the same RCM were referred to as "RCM simulations". In total, there were 4 GCM simulations (average of three members) and 3 RCMs simulation (average of four members). The analyses in this study are based on the outputs from these simulations.

\section{METHODS}

For each grid within the NARCliM domain for each time interval in the outputs, wet bulb temperature is calculated using simulated temperature, pressure and relative humidity for 12 simulations, each with three time periods (1990-2009, 2020-2039 and 2060-2079).

Wet bulb temperatures below $-2{ }^{\circ} \mathrm{C}$ were considered as suitable for snowmaking (Hennessy et al, 2008), as this corresponds to peak efficiency of snowmaking (snow can be made at much warmer temperatures at increasing cost). Time for suitable snowmaking is accumulated for each month and each year which is used to analyse monthly distribution and inter-annual variability.

The changes in the number of hours suitable for snowmaking, hereafter suitable snowmaking hours, are expressed as differences and relative changes between the future epochs (2020-2039 and 2060-2079) and the historical baseline epoch (1990-2009). The results for each ensemble member were averaged to get the ensemble mean.

Table 2. Location and elevation for 4 sites

\begin{tabular}{|c|c|c|c|}
\hline Sites & Latitude & Longitude & Elevation (m) \\
\hline Site 1 & -36.345 & 148.414 & 1904 \\
\hline Site 2 & -36.500 & 148.300 & 1681 \\
\hline Site 3 & -36.863 & 147.273 & 1809 \\
\hline Site 4 & -37.131 & 146.483 & 1499 \\
\hline
\end{tabular}

We selected 4 locations with different elevation to analyse differences in snowmaking condition between them. Wet bulb temperature, as a proxy for snowmaking conditions, was extracted to estimate and analyse changes in the suitable snowmaking hours at each location. The 4 sites are located at different elevations throughout the Australian Alps, loosely categorised as lower elevation (below 1500m), and higher elevation (above 1700m) sites (Table 2). 


\section{RESULTS}

In this section, we will first present suitable snowmaking hours over the Australian Alps, how this changes into the future and the seasonal variation, then we will present results for the 4 Australian Alps locations.

\subsection{Annual mean and change in suitable snowmaking time}

Annual mean and change in suitable snowmaking hours are calculated for each of the 12 ensemble members. The ensemble mean is presented in Figure 1.

Higher elevation areas have more suitable snowmaking hours compared to lower elevation areas, with practically zero snow making hours below 500m (Fig 1a). In the baseline historical epoch, there are more than 600 suitable snowmaking hours a year for high elevation areas (above 1700m) and less than 100 suitable snowmaking hours a year for lower elevation areas (below 1500m).

Large decreases in suitable snowmaking hours is projected for 2020-2039 and 2060-2079 relative to 1990-2009 (Fig 1b,c), with some lower elevation sites projected to become unsuitable for making snow and higher elevation sites projected to have about 300 fewer suitable snowmaking hours. The largest relative changes are projected for lower elevation areas, with up to $80 \%$ fewer suitable snowmaking hours in the future (not shown).
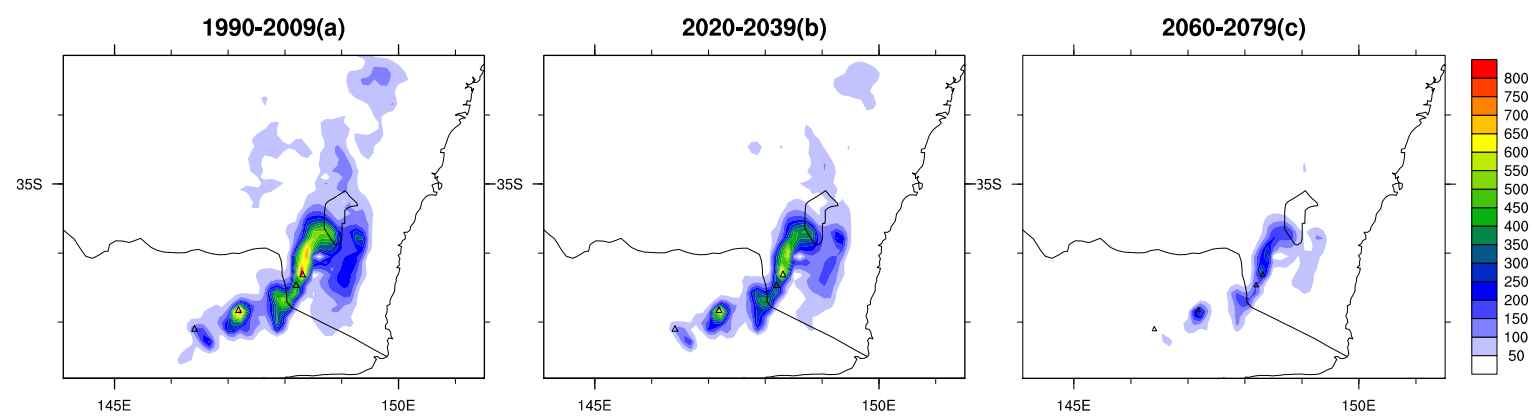

Figure 1. Ensemble mean of suitable snowmaking condition for 1990-2009, 2020-2039 and 2060-2079 (unit: hours). Four triangles show locations of the four sites.

\subsection{Monthly variation in time suitable for snow making}

Accumulated monthly suitable snowmaking hours is presented in the Figure 2. The three solid lines are ensemble mean for 12 NARCliM ensemble for historical and future periods. The three dashed lines are for the best scenario (largest value in 12 ensemble), and dotted lines are for the worst scenario (smallest value in 12 ensemble).

Across the Australian Alps, compared to the historical baseline epoch there is a clear decrease in the absolute number of suitable snowmaking hours into the future, but the seasonal distribution is relatively unchanged, with the peak occuring in winter (Jun-Jul-Aug). However, there is a significant contraction of the entire season, with much fewer suitable snowmaking hours in the shoulder seasons (Apr-May and Sept-Oct), with slightly fewer hours in spring months. The largest absolute decreases are projected to occur in winter. The differences between the best and the worst scenarios are very large, especially for the winter season. This implies that there is large uncertainty within the ensemble.

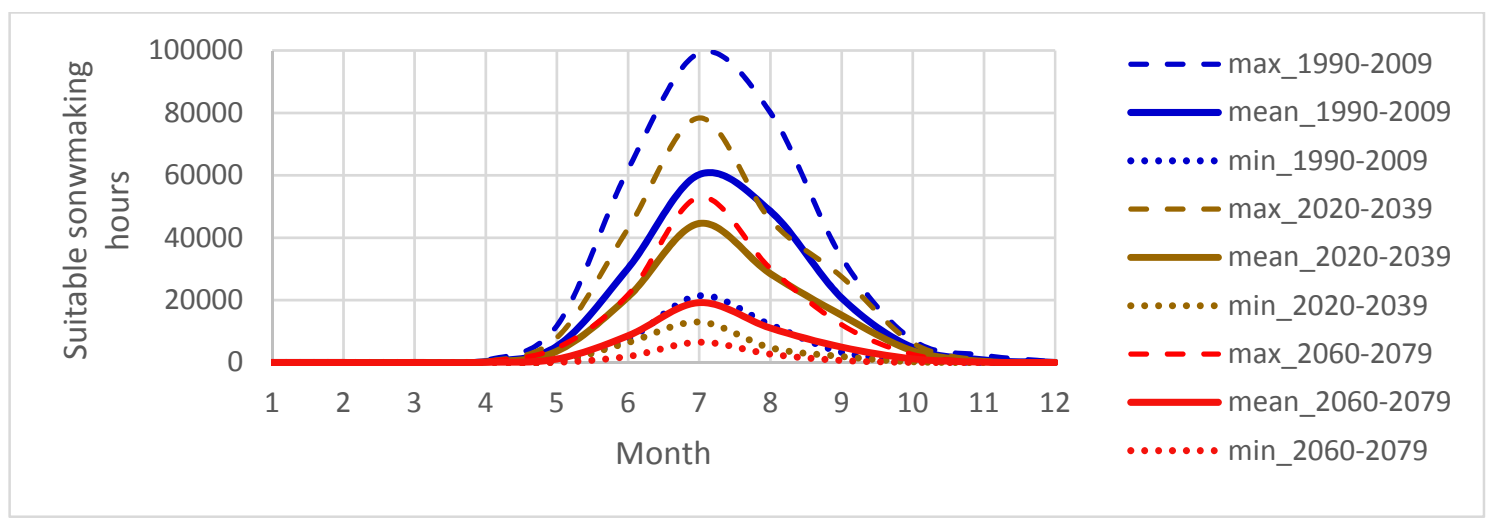

Figure 2. Simulated monthly distribution of suitable snowmaking condition for the Australian Alps for best, mean and worst scenarios (unit: hours) 


\subsection{Difference between GCM/RCM simulations}

Changes in suitable snowmaking hours for 2060-2079 relative to 1990-2009 are large for the Australian Alps. Differences in projections across GCM simulations are large, although they all project larger decreases in lower elevation areas sites than in higher elevation areas. Simulations based on CCCMA project the largest decreases in suitable snowmaking hours for lower elevation (more than 90\%) and higher elevation areas (more than $70 \%$ ). Simulations driven by MIROC project similar decreases for lower elevation areas, but smaller decreases for higher elevation areas (60-70\%). ECHAM and CSIRO driven simulations both project less severe changes, about half those of CCCMA and MIROC.
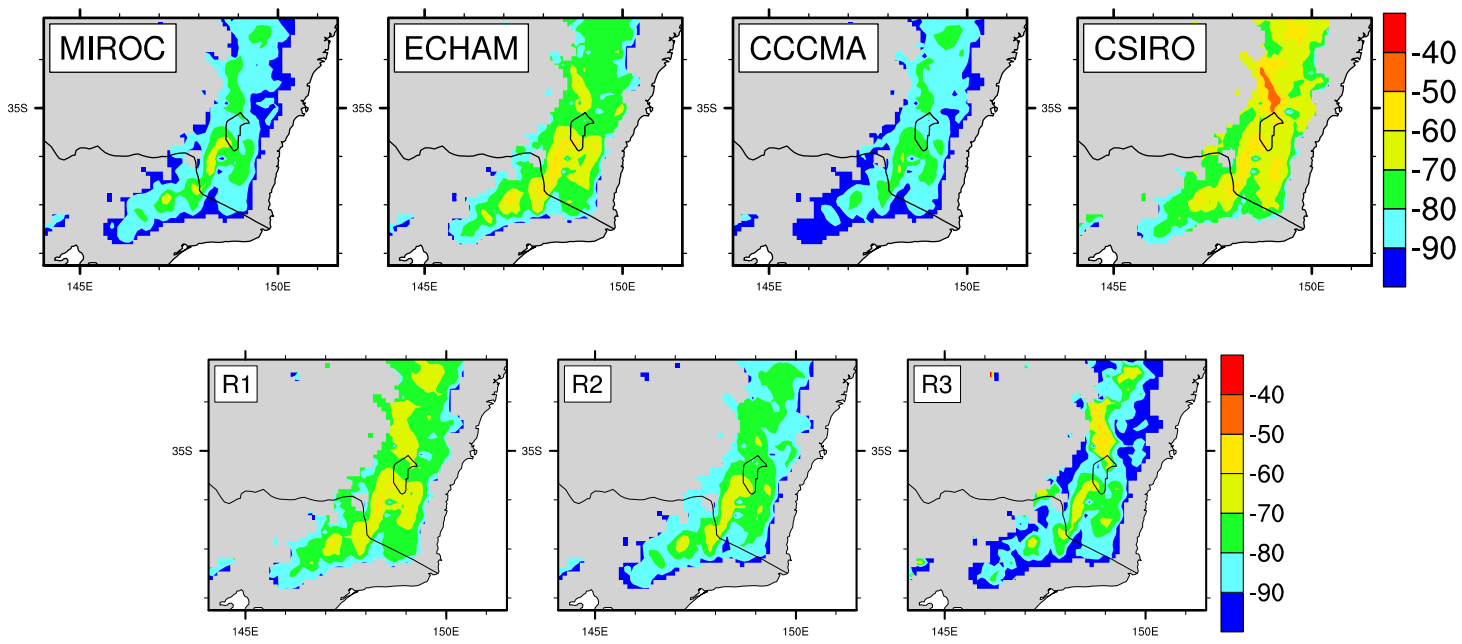

Figure 3. Relative changes in snowmaking condition for 2060-2079 relative to 1990-2009 for 4 GCM and 3 RCM simulations (unit: \%).

Three RCM simulations generally project similar decreases in suitable snowmaking hours for the Australian Alps with $60-70 \%$ decreases for higher elevation areas and $80-90 \%$ decreases for lower elevation areas. For areas outside of the alpine boundary, there are some differences between three RCM simulations as R3 simulations projected slightly larger increase in temperature for the future.

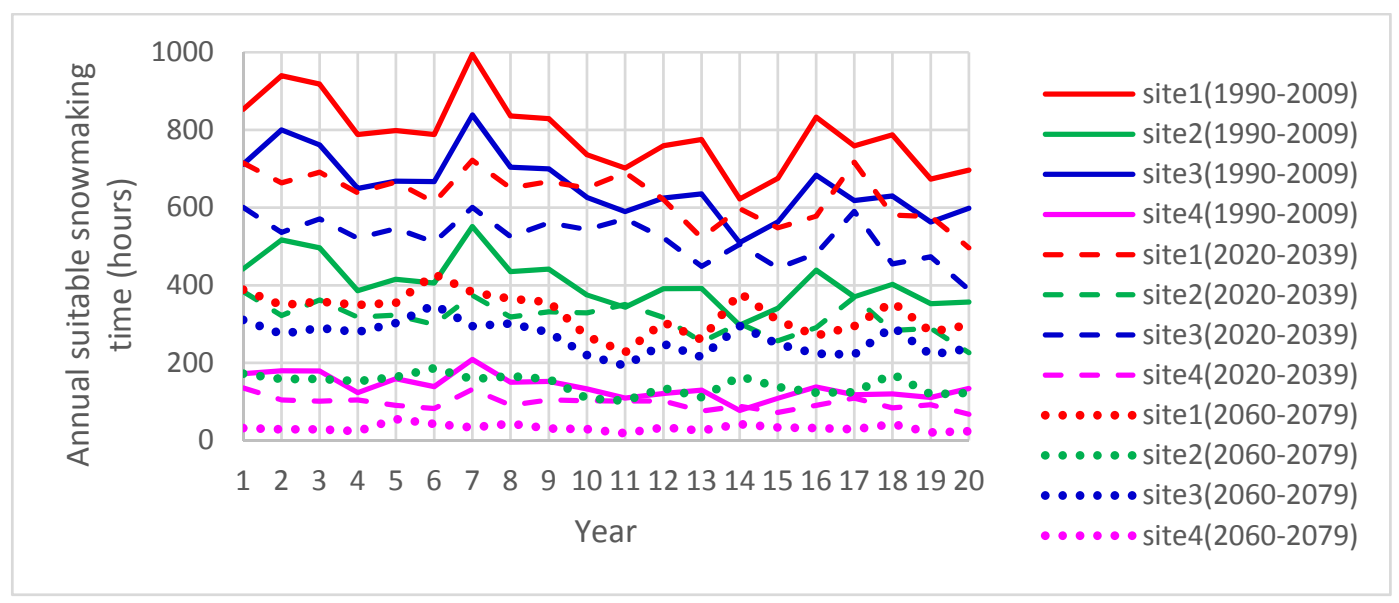

Figure 4. Inter-annual variation of suitable snowmaking hours for four locations

\subsection{Inter-annual variation for selected sites}

Suitable snowmaking hours have clear inter-annual variability (Figure 4). Here we show results for 4 locations at different elevations as an example. Locations at similar elevations generally have almost the same variation. Correlation of suitable snowmaking hours across different sites is related to elevation, with those sites at higher elevation areas correlating the best (more than 0.9). 
A clear decrease in suitable snowmaking hours can be observed at all sites (solid vs dotted lines in Figure 4) with larger absolute decreases for higher elevation sites

\subsection{Monthly variation for selected sites}

Within the model, July is the best time for making snow for all locations. The period of high suitable snowmaking hours across the year is longer (shorter) for higher (lower) elevation locations which starts earlier (later) and finishes later (earlier). Larger decreases in suitable snowmaking hours are projected for all locations, especially in the peak month, July, for higher elevation locations. Under a future climate, the period of suitable snowmaking hours will get shorter (start later and finish earlier) at all locations.

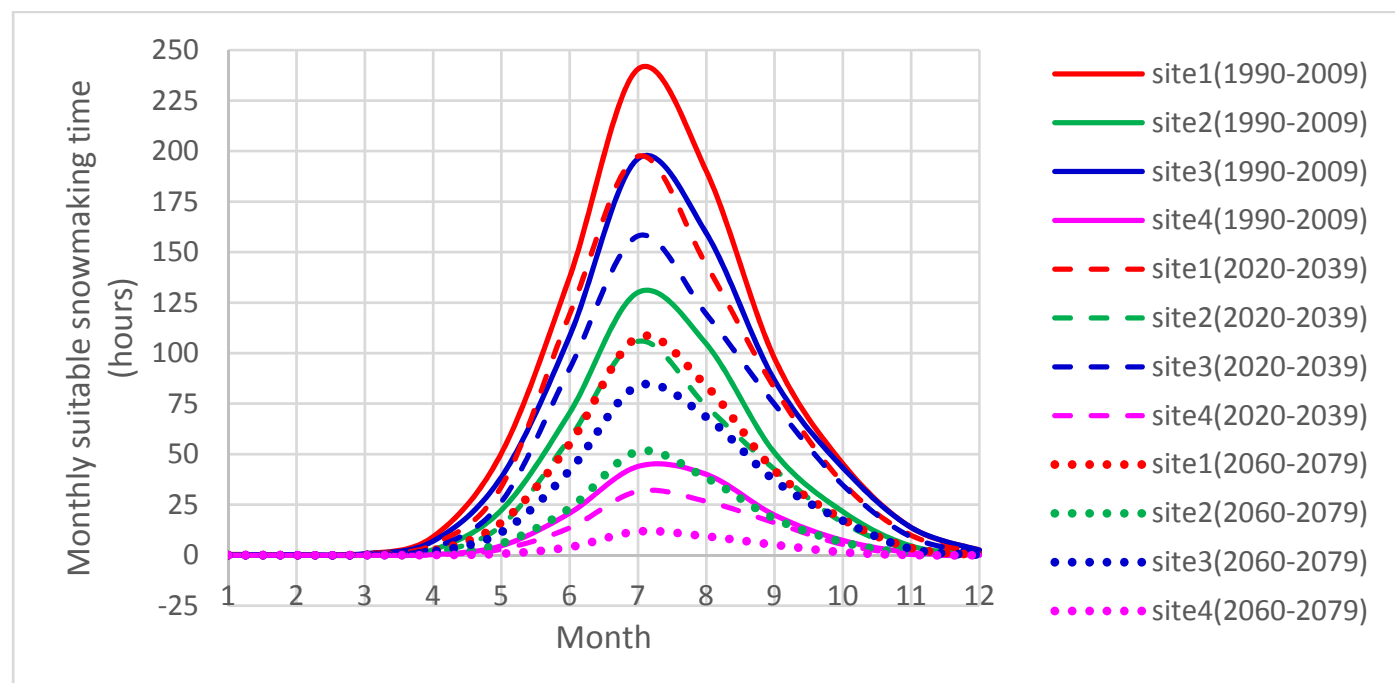

Figure 5. Ensemble mean duration of temperature inversion for 1990-2009, and changes in duration for 20202039 and 2060-2079 relative to $1990-2009$

\section{DISCUSSION AND CONCLUSIONS}

The results shown in this paper are the ensemble mean and change in ensemble mean. The results across the ensemble members reflect a robust projection of decreased suitable snowmaking hours into the future. However the magnitude of this decrease is less robust, with large differences between GCM simulations (although there is good agreement between the RCM ensemble members).

CCCMA3.1 and MIROC3.2 models both project wetter conditions into the future, while ECHAM5 and CSIROMK3.0 project drier conditions. However, CCCMA3.1 and ECHAM5 both project an extremely warm future, while the MIROC3.2 and CSIRO-MK3.0 future is only slightly warmer. No consistent correlation of moisture or temperature suggest wetness is just as critical as temperature to changes in suitable snowmaking hours. This indicates that large scale circulation must play a dominant role in how the frequency of suitable snowmaking hours may change into the future. This component is more difficult to categorise between models.

The results are for the specific locations shown in table 1. As ski courses span hundreds of meters in altitude, it's possible to have more suitable snowmaking hours for higher areas of each site.

The projections indicate a large decrease in suitable snowmaking hours for the Australian Alps with larger absolute decreases for higher elevation areas and larger relative decreases for lower elevation areas. The period each year when suitable snowmaking hours occur will be shorter for all areas, and may not occur for lower elevation locations in the future.

\section{ACKNOWLEDGMENTS}

This work is made possible by funding from the NSW Office of Environment and Heritage lead NSW/ACT Regional Climate Modelling Project (NARCliM), and the Australian Research Council as part of the Future Fellowship FT110100576 and Linkage Project LP120200777. The modelling work was undertaken on the NCI high performance computers in Canberra, Australia, which is supported by the Australian Commonwealth Government. 


\section{REFERENCES}

Bhend, J., J. Bathols, and K. Hennessy (2012). Climate change impacts on snow in Victoria. CSIRO report for the Victorian Department of Sustainability and Environment. Page 42, http:/www.climatechange.vic.gov.au/home/climate-change-impacts-on-snow-in-victoria,- 2013.

Davis C.J. (2013). Towards the development of long-term winter records for the snowy mountains. Australian Meteorological and Oceanographic Journal, 63(2):303-314.

Di Luca A., Evans J.P. and Ji F. (2017). Australian snowpack in the NARCliM ensemble: evaluation, bias correction and future projections. Climate Dynamics, under review.

Evans J.P., Ekstrom M and Ji F. (2012). Evaluating the performance of a WRF physics ensemble over SouthEast Australia, Climate Dynamics, 39:1241-1258, DOI 10.1007/s00382-011-1244-5

Evans J.P., Ji F., Abramowitz G., Ekstrom M. (2013a). Optimally choosing small ensemble members to produce robust climate simulations. Environmental Research Letters, 8, 044050, doi:10.1088/1748-9326/8/4/044050

Evans J.P., Fita L., Argüeso D. and Liu Y. (2013b). Initial NARCliM evaluation. In Piantadosi, J., Anderssen, R.S. and Boland J. (eds) MODSIM2013, 20th International Congress on Modelling and Simulation. Modelling and Simulation Society of Australia and New Zealand, December 2013, pp. 2765-2771.

Evans J.P., Ji F., Lee C., Smith P., Argüeso D., Fita L. (2014). Design of a regional climate modelling projection ensemble experiment - NARCliM, Geosci Model Dev 7(2), 621-629, doi: 10.5194/gmd-7-621-2014

Fiddes S.L., Pezza A.B., and Barras V. (2015) A new perspective on Australian snow. Atmospheric Science Letter. 16(3):246-252.

Fita L., Evans J.P., Argueso D., King A.D. and Liu Y. (2016). Evaluation of the regional climate response to large-scale modes in the historical NARCliM simulations. Climate Dynamics, doi: 10.1007/s00382-016-3484-X.

Harris R.M.B., Remenyi T. and Bindoff N.L. (2016). The potential impacts of climate change on Victoria Alpine Resorts. A report for the Alpine Resorts Co-ordinating Council.

Hennessy K.J., Whetton P.H., Walsh K., Smith I.N., Bathols J.M., Hutchinson M., and Sharples J. (2008). Climate change effects on snow conditions in mainland Australia and adaptation at ski resorts through snowmaking. Climate Research, 35(3):255-270.

Ji F., M. Ekstrom, J.P. Evans and J. Teng (2014). Evaluating rainfall patterns using physics scheme ensembles from a regional atmospheric model, Theoretical and Applied Climatology, 115:297-304, DOI: 10.1007/s00704013-0904-2

Ji F., Evans J.P., Teng J., Scorgie Y., Argüeso D., and Di Luca A. (2015). Evaluation of long-term precipitation and temperature WRF simulations for southeast Australia. Climate Research, under review.

Nicholls N. (2005). Climate variability, climate change and the Australian snow season. Australian Meteorological Magazine, 54(3):177-185.

NIEIR (2006). The economic significance of the Australian alpine resorts - Summary report. Prepared for: Alpine Resorts Co-ordinating Council

Olson R., Evans J.P., Di Luca A., and Argüeso D. (2016). The NARCliM project: model agreement and significance of climate projections. Climate Research, 69:209-227.

Pickering C. (2007). Climate change and other threats in the Australian alps. In M Taylor and P Figgis, editors, Protected Areas: buffering nature against climate change, pages 28-34. WWF-Australia, Sydney.

Ruddell, A. R, Budd W.F., Smith I.N., Keage P.L., and Jones R. (1990). The south east Australian alpine climate study. A report by the Meteorology Department, University of Melbourne for the Alpine Resorts Commission.

Skamarock WC, Klemp JB, Dudhia J, Gill DO, Barker DM, Duda MG, Huang XY, Wang W, Powers JG (2008). A Description of the Advanced Research WRF Version 3, NCAR Technical Note, NCAR, Boulder, CO, USA.

Slatyer R. (2010). Climate change impacts on Australia's alpine ecosystems. The ANU Undergraduate Research Journal, 2:17.

Timbal B., Ekstrom M., Fiddes S.L., Grose M., Kirono D.G.C., Lim E., Lucas C., and Wilson L. (2016). Climate change science and Victoria. Bureau Research Report No. 014.

Whetton P.H., Haylock M.R., and Galloway R. (1996). Climate change and snow-cover duration in the Australian Alps. Climatic Change, 32(4):447-479. 